\title{
Synthesis of Rutile-Rich Corundum/Rutile Functionally-Graded Materials with Different Precursors
}

\author{
Suminar Pratapa, Khusnul Umaroh and Frissa Erina Herdiyanti \\ Physics Department, Institute of Technology Sepuluh Nopember (ITS), Surabaya \\ e-mail: suminar_pratapa@physics.its.ac.id
}

Received 16 November 2010, Revised 13 February 2011, Accepted 15 April 2011

\begin{abstract}
Synthesis of corundum/rutileFGMS had been done with five repeated infiltrations. Preforms were made from corundum powder which were presintered at $1000^{\circ} \mathrm{C}$ for 1 hour to obtain green body porosity of around $54 \%$. The infiltration was performed by repeatedly fully immersing the preforms in $\mathrm{TiCl}_{3}$ and $\mathrm{Ti}\left(\mathrm{SO}_{4}\right)_{2}$ solutions (approximately $20 \% \mathrm{w} / \mathrm{v}$ ). The infiltrated preforms were then calcined at $1200^{\circ} \mathrm{C}$ for 2 hours. Phase characterisation using X-Ray Diffractometry (XRD) indicated that peak intensity of rutile increased with number of infiltration. Further observation showed that maximum gain of rutile was obtained from preforms which were fully immersed in the $\mathrm{TiCl}_{3}$-containing solution. Phase composition study at various depths for the $\mathrm{TiCl}_{3}$-containing samples using XRD showed that the content of rutile decreased with depth from $54 \%$ at the surface, $32 \%$ at $0.2 \mathrm{~mm}$, $20 \%$ at $0.4 \mathrm{~mm}$ and $17 \%$ at $0.6 \mathrm{~mm}$, while that for corundum increased complementarily. The phase composition results implied that synthesis of rutile-rich corundum/rutile functionally-graded materials has been successful using such precursor with multiple infiltration.
\end{abstract}

Keywords: Corundum; Rutile; FGMs; Infiltration method; XRD phase composition.

\section{Introduction}

Functionally-graded materials (FGMs) are composites with graded composition characters which may show smooth changes in physical, mechanical or thermal properties between their sides ${ }^{1)}$. Due to its graduality in composition and hence physical or mechanical properties, such kind of composite is considered as a potential candidate for applications with extreme environment such as aerospace and rocket blasting tube materials ${ }^{2}$.

Various types of methods for synthesising ceramic-based FGMs have been utilised by others, namely spark plasma sintering ${ }^{3)}$, chemical vapour deposition $^{4}$, metallurgical route ${ }^{5}$ and percolation of molten glass ${ }^{6}$. Among these methods, possibly the simplest but promosing one is by liquid infiltration ${ }^{7-9)}$. The method involve the preparation of a porous body which shoould be sufficiently strong for liquid infiltration, followed by infiltration with a liquid containing a certain precursor. The infiltrated body is then heated at certain temperature to obtain the desired phase. Our previous work, however, showed that a single infiltration with commercial solution gave low content of the desired phase ${ }^{8)}$ and also abrupt change in phase composition with depth. These issues became our attention since controlling phase content and graduality would result in more appropriate physical properties in applications.

In this paper we report the use of solutions which were made in our laboratory and the use of multiple infiltration method to give controlled composition of phases in corundum/rutile functionally-graded materials. Focus is paid mainly to the phase composition study using $\mathrm{x}$-ray diffraction data. Prediction on the production of functionally- graded materials based on the excellent thermal shock resistant $\mathrm{Al}_{2} \mathrm{TiO}_{5}$ is also presented.

\section{Materials and Methods}

The main raw materials in this research were high-purity $\alpha-\mathrm{Al}_{2} \mathrm{O}_{3}$ (Sigma-Aldrich) and excellentpurity $\mathrm{Ti}$ (Merck) powders. The green bodies were of presintered corundum $\left(\alpha-\mathrm{Al}_{2} \mathrm{O}_{3}\right)$ powder with apparent porosity around $54(2) \%$. These green bodies were made by uniaxially pressing the powder in a metal die to a pressure of $37 \mathrm{MPa}$ to yield a cylindrical sample of height $2 \mathrm{~mm}$ and diameter $1.2 \mathrm{~mm}$. Partial sintering at $1000^{\circ} \mathrm{C}$ for 60 minutes was used to increase the strength and retain the porosity of the green body prior to infiltration. The solutions were made by dissolving Ti powder in $\mathrm{HCl}$ or $\mathrm{H}_{2} \mathrm{SO}_{4}$, resulting in solutions containing $\mathrm{TiCl}_{3}$ or $\mathrm{Ti}(\mathrm{SO})_{4}$. The approximate amount of each precursor in the solution was $20 \%(\mathrm{w} / \mathrm{v})$. Infiltration was done 5 times followed by calcination at $1200^{\circ} \mathrm{C}$ for 2 hours to obtain rutile.

Phase characterisation was done using x-ray diffractometry (XRD) and data analyses were performed using Graphics \& Identify and Rietica ${ }^{10)}$ softwares. In-depth analysis were done by collecting x-ray diffraction data from surfaces of samples after polishing at designated depth and then analysed them.

\section{Results and Discussion}

Figure 1 shows mass gain by corundum porous green bodies after multiple infiltration using solutions containing $\mathrm{Ti}\left(\mathrm{SO}_{4}\right)_{2}$ or $\mathrm{TiCl}_{3}$. Each mass gain was measured after drying at around $60-70^{\circ} \mathrm{C}$. The figure indicate that infiltration has resulted in introduction of $\mathrm{TiO}_{2}$ precursor ${ }^{11,12)}$ and the amount of the solution diffusing into the green bodies increases with number 
of infiltration. In this case, however, the presence of rutile, the amount of the precursor at surface and how it is distributed within the green bodies is not known yet. It is therefore imperative to investigate the phase compositional character throughout the samples by $\mathrm{XRD}$. The investigation was done at room temperature after calcining the infiltrated samples at $1200^{\circ} \mathrm{C}$ at which rutile is completely formed ${ }^{8)}$.

Figure 2 shows the XRD patterns for the surface of the calcined $\mathrm{Ti}\left(\mathrm{SO}_{4}\right)_{2}$-containing samples (Fig. 2a) and $\mathrm{TiCl}_{3}$-containing samples (Fig. 2b) with number of infiltration. It is obvious that rutile [the most intense peak is at $\left.2 \theta \approx 27.5^{\circ}\right]^{13)}$ is hardly observed in the $\mathrm{Ti}\left(\mathrm{SO}_{4}\right)_{2}$-containing samples. Further observation to the samples showed that larger nominal amount gained by the $\mathrm{Ti}\left(\mathrm{SO}_{4}\right)_{2}$-containing samples resulted in a thick-film-like layer at the surface which is easily delaminated. This layer is possibly due to the viscousity of the solution which, by visual observation, is relatively higher than the solution containing $\mathrm{TiCl}_{3}$. By contrast, sharp peaks of rutile are observed in the less- viscous $\mathrm{TiCl}_{3}$-containing samples. In this type of samples, multiple infiltration clearly improves the amount of rutile at the surface. Therefore, controlling the amount of infiltrated solution can be done by multiple infiltration. This step is rather similar to a study on the formation graded Al$\mathrm{Ni}$ nanocomposites ${ }^{14)}$. It should be noted, however, that viscousity of the solution plays an important role in acquiring the desired phase. In this study, we then chose $\mathrm{TiCl}_{3}$ as the rutile precursor solution.

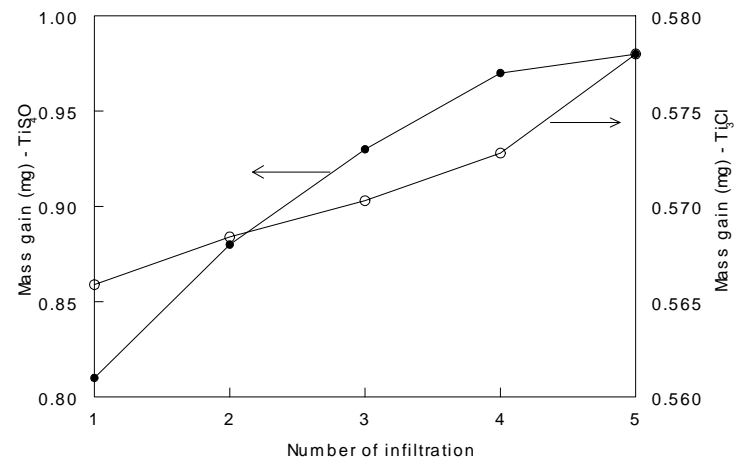

Figure 1. Green body mass gain after multiple infiltration using solutions containing either $\mathrm{Ti}\left(\mathrm{SO}_{4}\right)_{2}$ or $\mathrm{TiCl}_{3}$. Each mass gain was measured after drying.

Phase content of the $\mathrm{TiCl}_{3}$-infiltrated sample after calcination at various number of infiltration was done using Rietveld analysis and the result is presented in Figure 3. Increasing relative weight fraction of rutile with number of infiltration is observed. Complementary behaviour is observed for the corundum content as expected since its nominal amount remains the same but its relative amount decreases due to the introduction of rutile through infiltration. An interesting feature of the phase composition character for these samples is that 5 times infiltration can produce as high as $54 \mathrm{wt} \%$ of rutile which was impossible in single infiltration as observed by others ${ }^{7,15)}$. Such result for the rutile-rich sample implies the possibility to obtain pure $\mathrm{Al}_{2} \mathrm{TiO}_{5}$ (AT) at the surface. The overall results for this number-ofinfiltration-dependent study also means that it is possible to control the amount of rutile at the surface as desired. This outcome emphasizes the importance of infiltration-based approach for synthesizing ceramic FGMs.

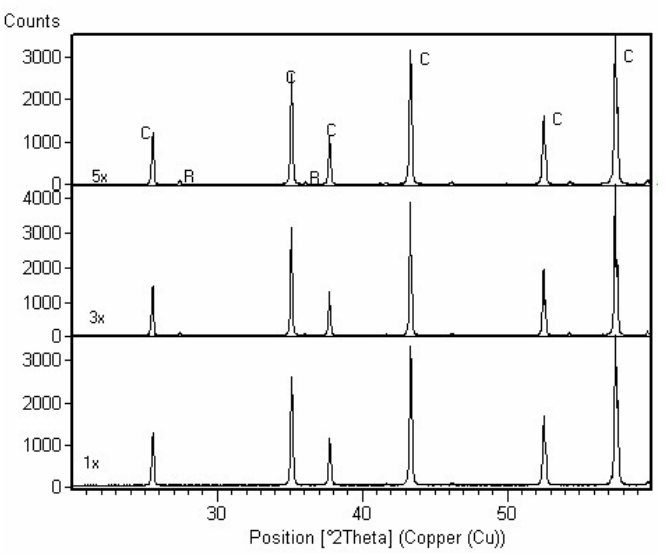

(a)

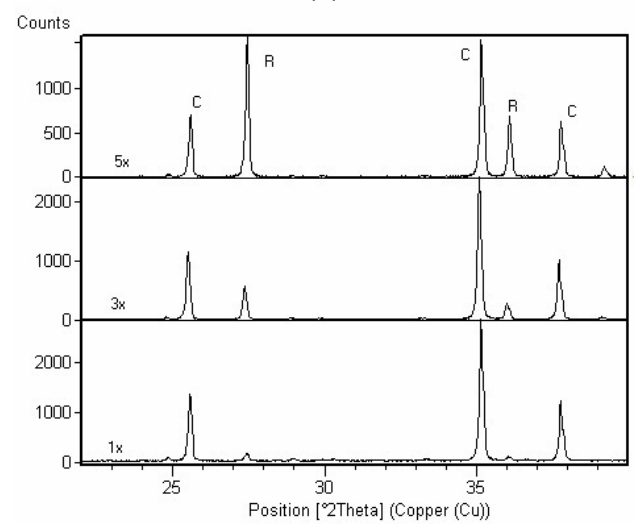

(b)

Figure 2. XRD patterns ( $\mathrm{Cu}$ target) for surfaces of corundum green bodies after multiple infiltration with (a) $\mathrm{Ti}\left(\mathrm{SO}_{4}\right)_{2}$-containing and (b) $\mathrm{TiCl}_{3}$-containing solutions and calcination. Legend: $\mathrm{C}=$ corundum, $\mathrm{R}=$ rutile.

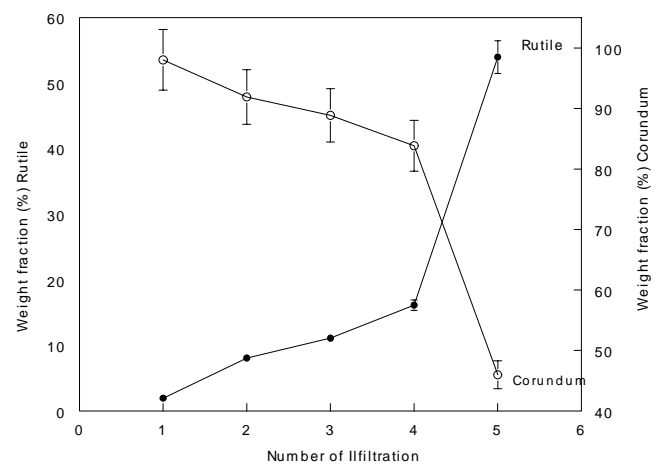

Figure 3. Rietveld phase composition with number of infiltration for the calcined $\mathrm{TiCl}_{3}$-containing samples. XRD data was measured at the surface of each sample. 
Further analysis was done to investigate the distribution of rutile in the ceramic body. XRD patterns for the $\mathrm{TiCl}_{3}$-containing solution samples with sample depth (only depth of $0.0,0.3,0.5$, and 0.7 patterns are shown to clarify the detail in the figure) are shown in Figure 3. It is clear from the figure that the intensity of rutile reduces with depth while the intensity of corundum, the first intense peak is at $2 \theta \approx$ $25.5^{\circ}{ }^{16)}$, relatively constant. This result indicates that a functionally-graded composite of corundum/rutile has been formed by this method. In order to quantify the amount of each phase at each depth, quantitative Rietveld phase analysis ${ }^{17)}$ was done by implementing Rietica software ${ }^{10)}$ to the XRD data at various depths. Use of this software for quantitative analysis with reasonable accuracy has been proven in several types of materials ${ }^{9,18)}$. The main analysis results are presented in Figure 5.

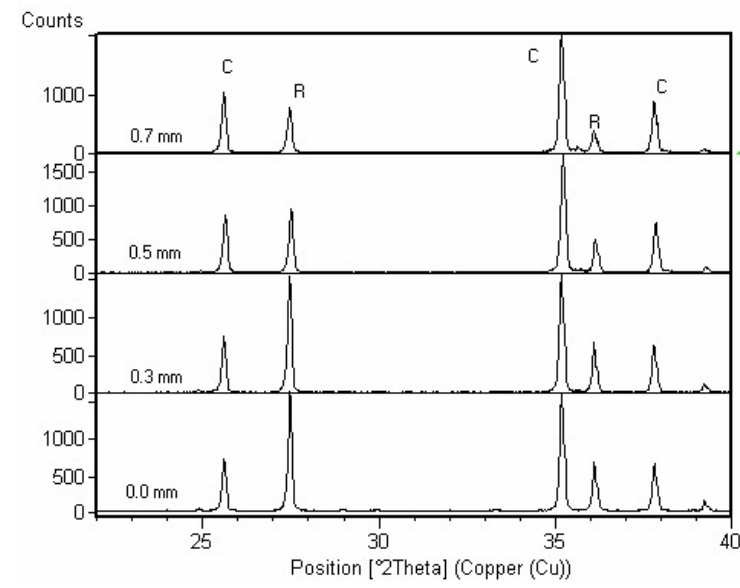

Figure 4. XRD patterns ( $\mathrm{Cu}$ target) at various depths for the calcined corundum sample after multiple infiltration for 5 times with a $\mathrm{TiCl}_{3}$-containing solution.

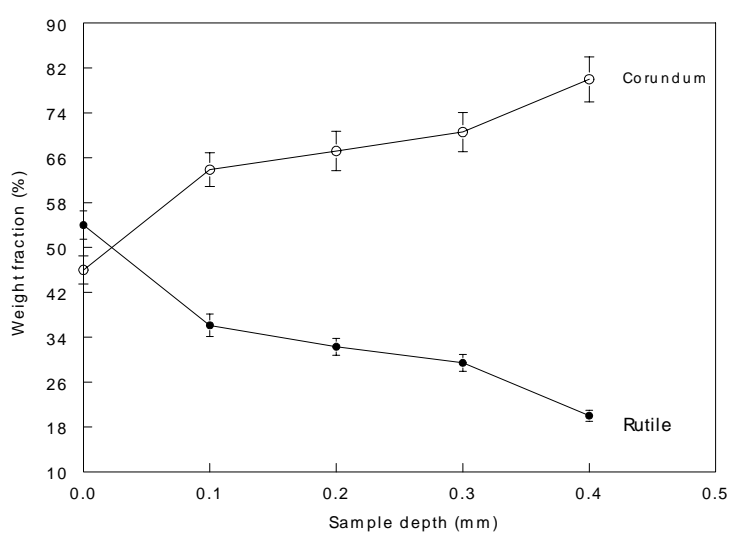

Figure 5. Rietveld phase composition with depth for the functionally-graded corundum/rutile composite produced by infiltration method with $\mathrm{TiCl}_{3}$-containing solution.

As can be seen from Figure 5, the amount of rutile decreases steadily with depth in complement to that of corundum. This depth-dependent composition is basic character of FGMs ${ }^{1,19)}$. As addition to the previous result where rutile content at the surface can be as high as $54 \mathrm{wt} \%$, Figure 5 also imparts the smooth graduality of rutile content which one again was very difficult to achieve with single infiltration ${ }^{11)}$. In general, multiple infiltration can be used to enrich a corundum preform porous bodies with rutile. Since corundum and rutile will react at around $1280{ }^{\circ} \mathrm{C}^{20)}$ to form AT, it is believed that sintering the infiltrated corundum bodies with such rutile content will produce AT-corundum functionally-graded composite materials with pure AT at one surface and pure corundum at the other side. Furthermore, the graduality of AT content can also be controlled.

\section{Conclusions}

The study shows that viscosity plays an important role in producing $\mathrm{FGMs}$, being relatively less-viscos solution such as $\mathrm{TiCl}_{3}$ in $\mathrm{HCl}$-water is more desireable. The study also shows that controlling rutile content and graduality of rutile-corundum FGMs can be achieved by selecting preforms with porosity around $50 \%$ and applying multiple infiltration. Rutile enrichment in this type of materials is believed to result in high-grade AT-corundum FGMs when sintering at high temperature is employed.

\section{Acknowledgement}

We thank Directorate for Higher Education, Ministry of National Education, Republic of Indonesia to provide funding for this research through Hibah Pascasarjana Project No. 10473/I2.7/PM/2009.

\section{References}

1. M. Koizumi, ed. The concept of FGM. Second International Symposium on Functionally Gradient Materials, 1992; Westerville, Ohio, San Fransisco, CA: The American Ceramic Society.

2. M. Sasaki, and T. Hirai, Fabrication and Properties of Functionally Gradient Materials, $J$ Ceram Soc Jap. 99, 970, 1991.

3. M. Belmonte et al., Continuous in situ functionally graded silicon nitride materials, Acta Materialia, 57, 2607, 2009.

4. S.N. Basu et al., Functionally graded chemical vapor deposited mullite environmental barrier coatings for Si-based ceramics, Journal of the European Ceramic Society, 28, 437, 2008.

5. M. Bhattacharyya, A.N. Kumar, and S. Kapuria, Synthesis and characterization of $\mathrm{Al} / \mathrm{SiC}$ and $\mathrm{Ni} / \mathrm{Al} 2 \mathrm{O} 3$ functionally graded materials, Materials Science and Engineering: A., 487, 524, 2008.

6. V. Cannillo et al., Glass-ceramic functionally graded materials produced with different methods, Journal of the European Ceramic Society, 27, 1293, 2007.

7. I. M. Low, R.D. Skala, and D. Zhou, Synthesis of functionally gradient aluminium titanate/alumina composites, Journal of Materials Science Letters, 15, 345, 1996. 
8. S. Pratapa, D. Hartanto, and E. Aprilyanti, Liquid infiltration technique for the synthesis of rutilealumina functionally-graded material, IPTEK (ITS Periodical), 12, 21, 2001.

9. K. Umaroh, S. Pratapa, ed. In-depth Phase Composition Profile of Functionally-Graded $\alpha$ $\mathrm{Al}_{2} \mathrm{O}_{3} / \mathrm{MgO}-\mathrm{Al}_{2} \mathrm{TiO}_{5}$. International Conference in Materials and Metallurgical Technology 2009 (ICOMMET 2009), 2009; Depatment of Material and Metallurgy, Institute of Technology Sepuluh November, Surabaya, Indonesia.

10. B. A. Hunter and Rietica, Newsletter of International Union of Crystallography, Commission on Powder Diffraction, 21, 1998.

11. S. Pratapa, B.H. O'Connor, and I.M. Low, Infiltration-processed functionally-graded aluminium titanate/zirconia-alumina composite:I, microstructural characterisation and physical properties, Journal of Materials Science, 33, 3037, 1998.

12. R. D. Skala, Development of a functionallygraded aluminium titanate/alumina composite, Ph.D. Desertation, Perth, Curtin University of Technology, 2000.

13. C. J. Howard, T. M. Sabine, and F. Dickson, Structural and thermal parameters for rutile and anatase, Acta Crystallographica B., 39, 462, 1983.
14. O. Aharon et al., Residual stresses and magnetic properties of alumina-nickel nanocomposites, Scripta Materialia, 50, 1209, 2004.

15. R. D. Skala, P. Manurung, and I. M. Low, Microstructural design, characterisation and indentation responses of layer-graded alumina/aluminium-titanate composites, Composites Part B: Engineering, 37, 466, 2006.

16. J. Lewis, D. Schwarzenbach, and H. D. Flack, Electric field gradients and charge density in corundum, $\alpha-\mathrm{Al}_{2} \mathrm{O}_{3}$, Acta Crystallographica, A38, 733, 1982.

17. D. L. Bish and S. A. Howard, Quantitative phase analysis using the Rietveld method, Journal of Applied Crystallography. 21, 86, 1988.

18. S. Pratapa, X-Ray Diffraction Phase Analyses for Granulated and Sintered Ceramic Materials, Makara Sains UI (Jurnal Terakreditasi DIKTI), 11, 65, 2007.

19. P. Sarkar, X. Huang, and P. S. Nicholson, Zirconia/alumina functionally gradiented composites by electrophoretic deposition techniques, Journal American Ceramic Society, 76, 1055, 1993.

20. B. Freudenberg and A. Mocellin, Aluminum Titanate Formation by Solid-State Reaction of Fine $\mathrm{Al}_{2} \mathrm{O}_{3}$ and $\mathrm{TiO}_{2}$ Powders, Journal American Ceramic Society, 70, 33, 1987. 